\title{
Heme oxygenase- 1 is a modulator of inflammation and vaso-occlusion in transgenic sickle mice
}

\author{
John D. Belcher, ${ }^{1}$ Hemachandra Mahaseth, ${ }^{1}$ Thomas E. Welch, ${ }^{1}$ Leo E. Otterbein, ${ }^{2}$ \\ Robert P. Hebbel, ${ }^{1}$ and Gregory M. Vercellotti ${ }^{1}$
}

\begin{abstract}
1Division of Hematology, Oncology and Transplantation, Department of Medicine and Vascular Biology Center, University of Minnesota, Minneapolis, Minnesota, USA. ${ }^{2}$ Harvard Medical School, Beth Israel Deaconess Medical Center, Department of Surgery, Boston, Massachusetts, USA.
\end{abstract}

\begin{abstract}
Transgenic sickle mice expressing $\beta^{\mathrm{s}}$ hemoglobin have activated vascular endothelium that exhibits enhanced expression of NF- $\kappa B$ and adhesion molecules that promote vascular stasis in sickle, but not in normal, mice in response to hypoxia/reoxygenation. Sickle mice hemolyze rbcs in vivo as demonstrated by increased reticulocyte counts, plasma hemoglobin and bilirubin, and reduced plasma haptoglobin. The heme content is elevated in sickle organs, which promotes vascular inflammation and heme oxygenase-1 expression. Treatment of sickle mice with hemin further increases heme oxygenase-1 expression and inhibits hypoxia/reoxygenation-induced stasis, leukocyte-endothelium interactions, and NF- $\mathrm{B}$, VCAM-1, and ICAM-1 expression. Heme oxygenase inhibition by tin protoporphyrin exacerbates stasis in sickle mice. Furthermore, treatment of sickle mice with the heme oxygenase enzymatic product carbon monoxide or biliverdin inhibits stasis and NF- $\mathrm{B}, \mathrm{VCAM}-1$, and ICAM-1 expression. Local administration of heme oxygenase-1 adenovirus to subcutaneous skin increases heme oxygenase-1 and inhibits hypoxia/reoxygenation-induced stasis in the skin of sickle mice. Heme oxygenase-1 plays a vital role in the inhibition of vaso-occlusion in transgenic sickle mice.
\end{abstract}

\section{Introduction}

Sickle cell disease (SCD) is a devastating hemolytic disease characterized by recurring episodes of painful vaso-occlusion, leading to ischemia/reperfusion injury and organ damage. Despite significant advances in our knowledge of the molecular defects in sickle hemoglobin $(\mathrm{Hb})$ and rbcs, we still lack a clear understanding of the pathophysiology and treatment of vaso-occlusion. Recently, the critical roles of oxidative stress, EC activation, and inflammation in vaso-occlusion have been recognized, in part because of the development of transgenic murine models of SCD (1). Intravital microscopy studies in murine models of SCD have demonstrated the critical role of adhesion molecules in the interaction of sickle rbcs and leukocytes with the vessel wall (2-8). P-selectin, VCAM-1, and ICAM-1 on the endothelium are required; blockade or knockout of any one of these adhesion molecules prevents either cytokine- or hypoxia-induced stasis $(2,4,6,7)$. Antiinflammatory agents such as dexamethasone or antioxidants also can ameliorate hypoxia/reoxygenation-induced abnormalities in blood flow of transgenic sickle mice $(2,3,5)$.

Excessive production of ROS in transgenic sickle mice plays a central role in promoting vascular inflammation, primarily through the activation of redox-sensitive transcription factors in the endothelium such as NF-KB and activator protein-1 (9). ROS are signaling molecules for a wide variety of inflammatory stimuli, such as LPS $(10,11)$ and TNF $(12)$. Thus, it is not surprising that the excess oxidative stress seen in transgenic sickle mice is accompanied by a proinflammatory state.

Nonstandard abbreviations used: $\mathrm{CO}$, carbon monoxide; Control-ADV, control adenovirus; dsDNA, double-stranded DNA; DSFC, dorsal skin fold chamber; $\mathrm{Hb}$, hemoglobin; $\mathrm{HO}$, heme oxygenase; $\mathrm{HO}-1-\mathrm{ADV}$, heme oxygenase-1 adenovirus; met-Hb, met-hemoglobin; $\mathrm{Ppm}$, parts per million; SCD, sickle cell disease; SnPP, tin protoporphyrin.

Conflict of interest: The authors have declared that no conflict of interest exists. Citation for this article: J. Clin. Invest. doi:10.1172/JCI26857.
A major source of oxidative stress in SCD is heme iron. Because of enhanced rates of $\mathrm{rbc}$ hemolysis, the endothelium of SCD patients is exposed to higher levels of ROS catalyzed by plasma $\mathrm{Hb}$, heme, and free iron (13). Heme, a ubiquitous, hydrophobic, iron-containing compound, greatly enhances cellular susceptibility to oxidant-mediated injury $(14,15)$. Heme readily escapes from met-hemoglobin (met-Hb) $(16,17)$ and rapidly intercalates into the membranes of cells.

The vasculature defends itself against reactive heme released during hemolysis of rbcs by inducing 2 cytoprotective genes, heme oxygenase (HO) and ferritin (18). Three isoforms of $\mathrm{HO}$ have been described: 2 constitutively expressed isoforms, HO-2 and HO-3 $(19,20)$, and a $32-\mathrm{kDa}$ inducible isoform, HO-1. HO-1 is transcriptionally inducible by a variety of agents, such as heme, oxidants, hypoxia, endotoxin, and cytokines (21).

HO- 1 is the rate-limiting enzyme in the catabolism of the heme. It breaks down the porphyrin ring to yield equal molar amounts of biliverdin, free iron, and carbon monoxide (CO). HO-1 plays a vital role in the cytoprotection of tissues (22). The induction of HO-1 is accompanied by the induction of apoferritin (18). Apoferritin, by its capacity to bind 4,500 iron molecules and through its heavy chain ferroxidase activity (23), can store nonreactive $\mathrm{Fe}^{3+}$ in the core of the ferritin complex. Induction of HO- 1 has been shown to protect tissues and cells against ischemia/reperfusion injury, oxidative stress, inflammation, transplant rejection, apoptosis, and cell proliferation $(22,24)$. Conversely, humans and mice deficient in HO-1 are especially prone to oxidant-mediated injury (25-27). HO-1 upregulation ameliorates inflammation, in part, through its ability to inhibit EC adhesion molecule expression and leukocyte adhesion in vivo and in vitro $(26,28,29)$. In contrast, inhibition of HO-1 increases adhesion molecule expression (30-32). Thus, it is reasonable to surmise that $\mathrm{HO}-1$ plays an important antiinflammatory role, particularly in SCD. 
Table 1

Sickle mice have intravascular hemolysis of rbcs

\begin{tabular}{lccc}
$\begin{array}{l}\text { Mouse } \\
\text { model }\end{array}$ & $\begin{array}{c}\text { Plasma } \\
\mathbf{H b} \\
(\mathbf{m g} / \mathbf{d l})\end{array}$ & $\begin{array}{c}\text { Plasma } \\
\text { haptoglobin } \\
(\% \text { of normal) }\end{array}$ & $\begin{array}{c}\text { Plasma } \\
\text { bilirubin } \\
(\mathbf{m g} / \mathbf{d l})\end{array}$ \\
Normal & $0.59 \pm 0.04$ & $100.0 \pm 46.1$ & $0.92 \pm 0.13$ \\
S+S-Antilles & $2.36 \pm 0.92^{\mathrm{A}}$ & $39.6 \pm 13.1^{\mathrm{A}}$ & $1.71 \pm 0.53^{\mathrm{A}}$ \\
BERK & $5.5 \pm 2.0^{\mathrm{A}}$ & $42.9 \pm 6.1^{\mathrm{A}}$ & $5.95 \pm 1.78^{\mathrm{A}}$ \\
\hline
\end{tabular}

Plasma $\mathrm{Hb}$ was measured by Drabkin's reagent. Plasma haptoglobin was measured by Western blotting and is expressed as a percentage of normal plasma haptoglobin, and total plasma bilirubin was measured colorimetrically by the diazo bilirubin method (84). $n=4-10$ mice per group. ${ }^{A} P<0.05$, normal versus sickle.

We now demonstrate that HO-1 is upregulated in transgenic sickle mice in response to an increased heme burden. Furthermore, we report that promoting additional increases in $\mathrm{HO}-1$ expression in transgenic sickle mice inhibits NF-кB/EC activation and downregulates $\mathrm{EC}$ adhesion molecule expression, which inhibits the binding of leukocytes to the vessel wall and prevents hypoxia/reoxygenation-induced vascular stasis. These findings suggest that $\mathrm{HO}-1$ is upregulated in SCD in response to the hemolysis of sickle rbcs and that additional increases in $\mathrm{HO}-1$ activity and/or its downstream products, in excess of the adaptive upregulation seen in transgenic sickle mice, inhibit vascular inflammation and vaso-occlusion. Agents that increase HO-1 activity or its products may provide new therapies to prevent or treat vaso-occlusion in SCD patients.

\section{Results}

S+S-Antilles and BERK sickle mice, based on their comparison with normal C57BL/ 6 control mice, have intravascular hemolysis as demonstrated by increased plasma $\mathrm{Hb}$, decreased plasma haptoglobin, and increased plasma bilirubin (Table 1). In data not shown, S+S-Antilles mice were minimally anemic (hematocrit $40.1 \% \pm 3.0 \%, P<0.05$ ) and BERK mice were severely anemic $(21.6 \% \pm 3.3 \%, P<0.05)$ compared with normal control mice $(42.9 \% \pm 1.5 \%)$. Reticulocyte counts, expressed as percentage rbcs, were elevated in S+S-Antilles $(11.2 \% \pm 2.4 \%, P<0.05)$ and BERK mice $(31.6 \% \pm 2.9 \%, P<0.05)$ compared with normal controls $(3.1 \% \pm 0.9 \%)$. S + S-Antilles and BERK mice also had elevated levels of ferric $\left(\mathrm{Fe}^{3+}\right)$ met-Hb in their blood $(1.0 \% \pm 0.2 \%$ and $2.3 \% \pm 0.8 \%$, respectively) compared with normal mice $(<0.1 \%)$. One way in which met-Hb can form in plasma is by reaction of ferrous $\left(\mathrm{Fe}^{2+}\right) \mathrm{Hb}$ with $\mathrm{NO}$, resulting in potential effects on $\mathrm{NO}$ and heme bioavailability $(33,34)$. Ferric $\left(\mathrm{Fe}^{3+}\right)$ heme can rapidly dissociate from met- $\mathrm{Hb}(16,17)$, thereby potentially providing a ready source of heme to the vasculature.

In data not shown, the organ histopathology of S+S-Antilles and BERK mice was examined; rbc congestion was seen in the lungs and livers of sickle mice but not in normal mice. The livers of sickle mice had areas of infarction and inflammation. Red blood cell congestion also was seen in other organs of sickle mice, including the kidneys and brain. Thus, both the mildly anemic S+S-Antilles and the severely anemic BERK models mimic the rbc congestion and infarction pathology seen in humans with SCD.

The rbc congestion was estimated by measurement of organ heme content by the pyridine-hemochrome method (35). The lungs and livers of S+S-Antilles mice had significantly more heme than those of normal mice (Table 2).
Do the excessive heme content and inflammation found in sickle organs promote increased HO-1 expression? To answer this question, HO-1 expression was measured by Western blotting in organ homogenates from normal and sickle mice. HO-1 expression was significantly increased in the lungs, livers, and spleens of $\mathrm{S}+\mathrm{S}$-Antilles and BERK mice compared with normal control mice (Figure 1). HO-1 expression was similar in S+S-Antilles and BERK mice despite higher plasma $\mathrm{Hb}$ concentrations in the BERK model, shown in Table 1.

Since $\mathrm{HO}-1$ and its products have documented antiinflammatory properties, a key question is whether additional upregulation of $\mathrm{HO}-1$ expression can inhibit vaso-occlusion and vascular inflammation in sickle mice. Since hemin is the most powerful inducer of HO-1, $\mathrm{S}+\mathrm{S}$-Antilles mice were injected i.p. with hemin at $40 \mu \mathrm{mol} / \mathrm{kg} / \mathrm{d}$ for 3 days. HO-1 levels in the lungs, liver, and spleen increased markedly in response to hemin injections (Figure 2A), demonstrating that $\mathrm{HO}-1$ can be even further upregulated in sickle mice that already have significant elevations in $\mathrm{HO}-1$ expression compared with normal mice. Figure 2B demonstrates HO- 1 activity in a $105,000-g$ microsomal fraction isolated from normal and sickle livers (36). The data in Figure 2 suggest that (a) hemin treatment of S+S-Antilles mice increases HO-1 even further; (b) HO-1 activity is elevated in the livers of $\mathrm{S}+\mathrm{S}$-Antilles mice compared with normal mice; (c) hemin treatment of normal mice increases HO-1 activity in the liver, but is still lower than that of untreated S+S-Antilles mice without hemin treatment; and (d) tin protoporphyrin (SnPP), a powerful inhibitor of HO-1, blocks hemin-induced increases in HO-1 activity. Immunohistochemistry of $\mathrm{HO}-1$ in frozen sections from the lungs, liver, and spleen of normal control mice and untreated and hemintreated sickle mice demonstrated increased endothelial staining of HO-1 in vessels of all organs from sickle mice compared with normal mice as well as increased parenchymal cell staining in the livers of hemin-treated sickle mice (data not shown).

To test whether further upregulation of HO-1 could prevent stasis in subcutaneous venules, $\mathrm{S}+\mathrm{S}$-Antilles and BERK mice with an implanted dorsal skin fold chamber (DSFC) were treated with injections of hemin $(40 \mu \mathrm{mol} / \mathrm{kg} / \mathrm{d}$, i.p.) or SnPP, a powerful inhibitor of $\mathrm{HO}-1$ activity $(40 \mu \mathrm{mol} / \mathrm{kg} / \mathrm{d}$, i.p.) for 3 days before exposure to hypoxia/reoxygenation. Remarkably, hemin-treated sickle mice whose HO-1 was further upregulated showed no evidence of stasis (Figure 3, A and B) after 1 hour of hypoxia and 1 hour of reoxygenation, while untreated $S+S$-Antilles mice had $12 \%$ of venules occluded and untreated BERK mice had $23 \%$ of vessels occluded. The HO-1 inhibitor SnPP did not prevent stasis in the venules of $\mathrm{S}+\mathrm{S}$-Antilles mice at 1 hour of reoxygenation (15\% static) and, in fact, made stasis worse after 4 hours of reoxygenation (25\% static) (Figure $3 \mathrm{~A})$. Thus, further upregulation of $\mathrm{HO}-1$ by injection of

Table 2

S+S-Antilles mice have increased heme content

\begin{tabular}{lcc} 
Mouse model & \multicolumn{2}{c}{ Heme content $(\mu \mathrm{g}$ heme $/ \mu \mathrm{g}$ DNA) } \\
& Lung & Liver \\
Normal & $8.9 \pm 4.1$ & $4.17 \pm 2.4$ \\
S+S-Antilles & $329.7 \pm 71.9 \mathrm{~A}$ & $20.4 \pm 2.7^{\mathrm{A}}$
\end{tabular}

The organs of untreated normal $(n=4)$ and S+S-Antilles $(n=4)$ mice in ambient air were homogenized, and the heme content was measured by the pyridine-hemochrome method (35) (mean \pm SD micrograms heme per microgram of organ DNA). ${ }^{\star} P<0.05$, normal versus sickle. 

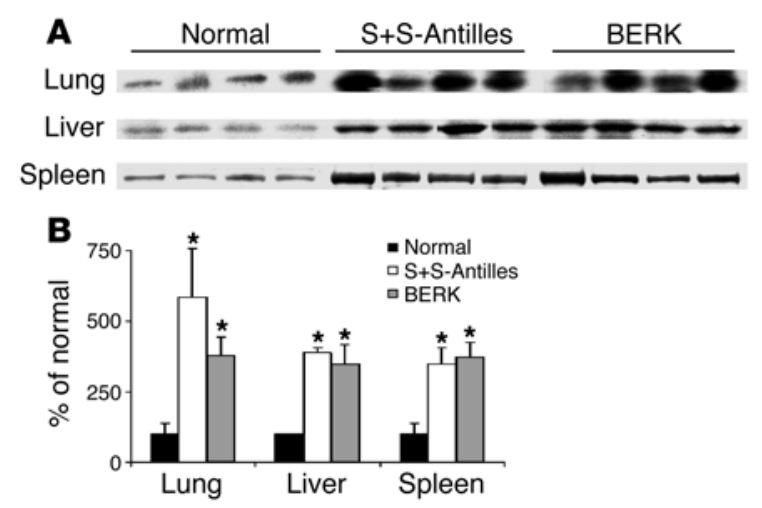

Figure 1

$\mathrm{HO}-1$ expression is elevated in the organs of sickle mice. Western blots for $\mathrm{HO}-1$ were performed on organ homogenates $(1 \mu \mathrm{g}$ of organ DNA per lane) from lungs, livers, and spleens of untreated normal, S+S-Antilles, and BERK mice. (A) The 32-kDa HO-1 bands are shown for each organ and each mouse. (B) The mean HO-1 band intensities $(n=4)$ $\pm \mathrm{SD}$ are expressed as a percentage of those in normal control mice. ${ }^{\star} P<0.05$, normal versus sickle.

hemin in both these mouse models of SCD prevented hypoxia/ reoxygenation-induced stasis.

But how does HO-1 inhibit stasis? To address this question, we examined the products of HO-1 enzymatic activity, $\mathrm{CO}$ and biliverdin, in the hypoxia/reoxygenation stasis model. S+S-Antilles mice breathing $\mathrm{CO}$ at 250 parts per million (ppm) $\mathrm{CO}$ in air for 1 hour each day for 3 days or injected with biliverdin $(50 \mu \mathrm{mol} / \mathrm{kg}$ i.p. $)$ at 16 hours and 2 hours before exposure to hypoxia $\left(7 \% \mathrm{O}_{2} / 93 \% \mathrm{~N}_{2}\right)$ for 1 hour and then reoxygenated in room air for 1 hour were protected against the development of stasis (Figure 4). Treatment with $\mathrm{CO}$ increased carboxy-Hb levels to $11.2 \% 1$ hour after treatment with $\mathrm{CO}$, and the levels decreased to less than $1 \% 24$ hours after each $\mathrm{CO}$ exposure (data not shown). Thus, $\mathrm{CO}$ inhalation prevented stasis even after carboxy-Hb levels had returned to base line. We see this same timing effect after balloon angioplasty in rats, in which 1 hour of $\mathrm{CO}$ inhalation given 1 week before angioplasty still protects against lesion development (data not shown).

\section{Figure 2}

Hemin increases HO-1 expression. (A) HO-1 expression can be further upregulated in the organs of sickle mice with hemin treatment. S+S-Antilles mice were either untreated or injected with hemin ( $40 \mu \mathrm{mol} / \mathrm{kg} / \mathrm{d}$, i.p.) for 3 days. Twenty-four hours after the third injection, the organs were harvested, and Western blots for $\mathrm{HO}-1$ were performed on lung, liver, and spleen homogenates ( $1 \mu \mathrm{g}$ of organ homogenate DNA per lane). The mean $\mathrm{HO}-1$ band intensities $(n=3) \pm \mathrm{SD}$ are expressed as a percentage of those in untreated $\mathrm{S}+\mathrm{S}$-Antilles mice (100\%), which represent the same untreated S+S-Antilles organs shown in Figure 1. Below each bar is a representative $\mathrm{HO}-1$ band from the Western blot. ${ }^{*} P<0.05$, untreated versus hemin. (B) HO-1 activity in normal and $\mathrm{S}+\mathrm{S}-$ Antilles livers. HO-1 activity was measured in microsomes isolated from another group of normal and $\mathrm{S}+\mathrm{S}$-Antilles sickle mice as previously described (36). Mice were untreated, injected with hemin $(40 \mu \mathrm{mol} / \mathrm{kg} / \mathrm{d}$, i.p.) for 3 days, or injected with hemin plus SnPP ( $40 \mu \mathrm{mol} / \mathrm{kg} / \mathrm{d}$ of each porphyrin, i.p.) for 3 days. Twenty-four hours after the third injection, the livers were harvested, microsomes were isolated at 105,000 $\mathrm{g}$, and $\mathrm{HO}-1$ enzymatic activity was measured. The results in triplicate are expressed as mean \pm SEM picomoles of bilirubin generated per milligram microsomal protein per hour. ${ }^{*} P<0.05$, normal versus sickle.
We have previously shown that activation of vascular endothelium plays an essential role in vaso-occlusion in transgenic sickle mice (2, 3). Antioxidants (3), antiinflammatory agents (2), and adhesion molecule-blocking antibodies (2) inhibit EC activation and hypoxia-induced vaso-occlusion. This inhibition is accompanied by decreased interactions of leukocytes with the vessel wall. We wondered whether hemin treatment would also decrease leukocyte rolling and adhesion along the endothelium of sickle mice. This was indeed the case. Hemin injections in S+S-Antilles mice blunted the increases in leukocyte rolling and adhesion induced by hypoxia/reoxygenation (Figure 5).

The decrease in leukocyte rolling and adhesion in sickle mice treated with hemin suggested that hemin treatments and HO-1 upregulation were inhibiting adhesion molecule expression on the vessel wall. We have previously shown that sickle mouse organs overexpress NF-кB, VCAM-1, and ICAM-1 compared with organs of normal mice $(2,3,37)$. So next we examined the effect of hemin on the expression of adhesion molecules and the inflammatory transcription factor NF-кB. Treatment of sickle mice with i.p. injections of hemin for 3 days markedly decreased NF- $\kappa$ B activation and VCAM-1 and ICAM-1 overexpression in sickle lungs, liver, and spleen (Figure 6). These decrements in vascular inflammation correlate with decreased hypoxia/reoxygenation-induced leukocyte-endothelium interactions and venular stasis in hemin-treated sickle mice, consistent with HO-1 inhibition of inflammation and vaso-occlusion.

Could the products of $\mathrm{HO}-1$, biliverdin and $\mathrm{CO}$, also be working their antistasis effects through inhibition of these inflammatory pathways? CO inhalation or i.p. injections of biliverdin markedly decreased NF-KB activation in the lungs of sickle animals (Figure 7). Thus, it appears that both $\mathrm{CO}$ and biliverdin, products of HO-1 degradation of heme, are antiinflammatory and can inhibit stasis in sickle mice.

Since hemin can have nonspecific effects in vivo, we also used a rat $\mathrm{HO}-1$ adenovirus construct (HO-1-ADV) to further increase $\mathrm{HO}-1$ expression in $\mathrm{S}+\mathrm{S}-$ Antilles sickle mice. This construct has been used successfully to overexpress $\mathrm{HO}-1$ in mouse organs in vivo (38). We added HO-1-ADV $\left(2 \times 10^{7} \mathrm{MOI}\right)$ for 48 hours directly to the subcutaneous skin of S+S-Antilles mice with an implanted
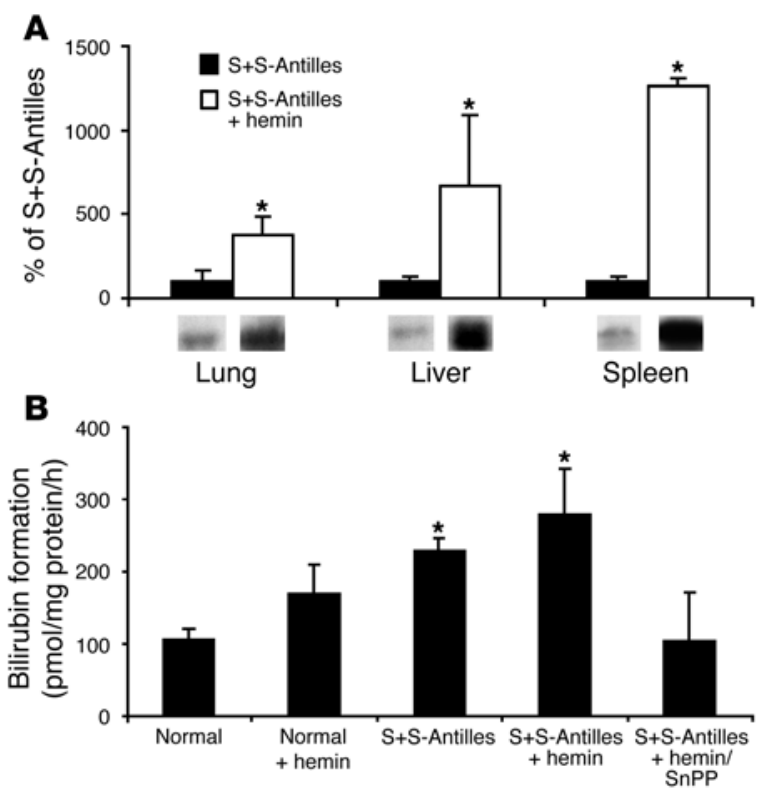


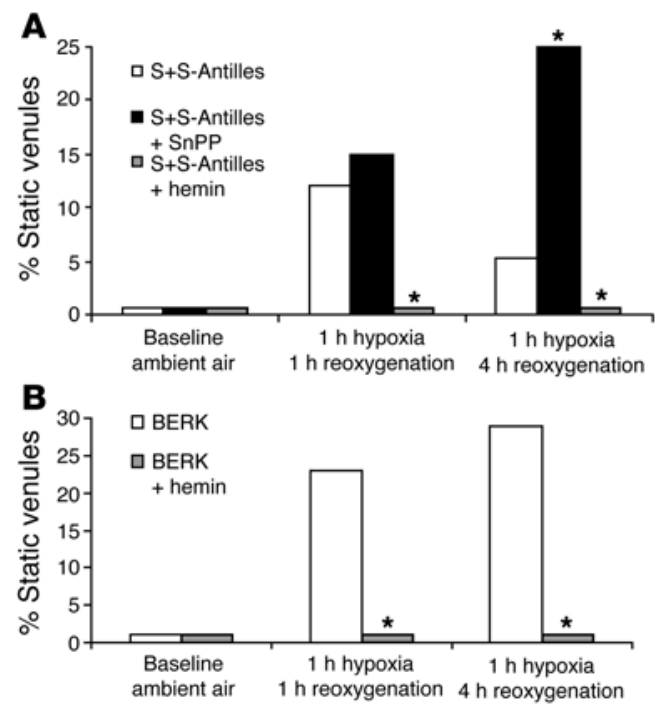

\section{Figure 3}

Further upregulation of $\mathrm{HO}-1$ by hemin inhibits stasis and $\mathrm{HO}-1$ inhibition by SnPP exacerbates stasis in sickle mice. S+S-Antilles (A) and BERK (B) mice with an implanted DSFC were untreated, injected with hemin ( $40 \mu \mathrm{mol} / \mathrm{kg} / \mathrm{d}$, i.p.) for 3 days, or injected with $\operatorname{SnPP}(40 \mu \mathrm{mol} / \mathrm{kg} / \mathrm{d}$, i.p.) for 3 days. Twenty-four hours after the third injection, stasis was measured after 1 hour of hypoxia $\left(7 \% \mathrm{O}_{2} / 93 \% \mathrm{~N}_{2}\right)$ and 1 hour and 4 hours of reoxygenation in room air. $n=3-10$ mice and a minimum of 20 venules per mouse. ${ }^{*} P<0.05$, untreated versus hemin or SnPP. The proportions of venules exhibiting stasis at each time point were compared using a $z$ test.

DSFC and saw approximately $225 \%$ induction of $\mathrm{HO}-1$ expression in the skin (Figure 8A) compared with that in untreated S+S-Antilles mice. Control adenovirus (Control-ADV) alone (empty vector without HO-1, $2 \times 10^{7} \mathrm{MOI}$ ) did not significantly increase HO-1 further. Most importantly, hypoxia/reoxygenation-induced stasis was inhibited after both 1 hour and 4 hours of reoxygenation in the subcutaneous skin of mice treated with HO-1-ADV (Figure 8B). Mice treated with the Control-ADV vector exhibited worsened stasis. These data support our hypothesis that additional upregulation of $\mathrm{HO}-1$ will be beneficial in preventing vaso-occlusion in SCD.

\section{Discussion}

These data highlight the critical importance of HO-1 in ameliorating vascular inflammation and vaso-occlusion in murine models of SCD. Nath and colleagues demonstrated increased HO-1 in the kidney vasculature of a patient with SCD as well as increased HO-1 in circulating ECs (39). Jison et al. (40) showed that sickle blood mononuclear cells have elevated $\mathrm{HO}-1$ and biliverdin reductase mRNA even during steady state. Thus, chronic hemolysis and oxidative stress in SCD result in upregulation of HO-1 in patients as well as in transgenic sickle mice. It is likely that during acute hemolytic crises the patient with SCD increases HO-1 even further to deal with the increased heme burden and oxidative stress. It is this upregulation that may facilitate the resolution of vaso-occlusion. This adaptation allows the degradation of toxic heme and the production of $\mathrm{CO}$, an antiinflammatory vasodilator; biliverdin and bilirubin, both antioxidants; and ferritin, an iron chelator.

Since we do not completely understand the pathobiology of human $\mathrm{SCD}$, it is impossible to know how well the sickle mouse models mimic human disease. Probably none of the models displays all of the attributes of human SCD. They can best be described as tools to understand human SCD (41). For our studies, the sickle mouse models mimic human SCD in several important ways: they have rbc sickling in response to hypoxia; hemolysis; organ pathology with rbc congestion and infarction as in the human disease; excessive ROS production; a vigorous and chronic inflammatory response with activated endothelium; and impaired blood flow, especially in response to hypoxia/reoxygenation $(2,4,7,37,42-45)$. Most of the studies described in this paper focused on the less severe murine model of SCD, the S+S-Antilles mouse (46), and fewer on the more severe murine model, BERK mice (47). However, BERK mice, which are more anemic (hematocrit $22 \%$ ) than S+S-Antilles mice, have similar levels of HO-1 expression, EC activation (2,37), and organ pathology with rbc congestion and infarction but respond to hypoxia/reoxygenation with even more vaso-occlusion. Manci and colleagues (48) reported that BERK mice were similar to humans with SCD in having erythrocytic sickling, vascular ectasia, intravascular hemolysis, exuberant hematopoiesis, cardiomegaly, glomerulosclerosis, visceral congestion, hemorrhages, multiorgan infarcts, pyknotic neurons, and progressive siderosis. However, the BERK mice differed from humans with SCD in having splenomegaly; splenic hematopoiesis; more severe hepatic infarcts; less severe pulmonary manifestations; no significant vascular intimal hyperplasia; and only a trend toward vascular medial hypertrophy. Thus, these notable differences warrant careful consideration when parallels to human SCD are drawn (48). Our studies suggest that HO-1 upregulation may be important in inhibiting vascular inflammation in these murine transgenic models of human SCD. It is uncertain whether HO-1 plays a similar role in human SCD patients. Linkage of additional HO-1 expression in these SCD mouse models to other endpoints such as improvements in hemolysis and anemia or organ pathology and lifespan, conditions more directly relevant to the human disease, would strengthen these findings as being potentially relevant to human SCD.

Based on our current understanding of the interrelationships of hemolysis, oxidative stress, EC activation, blood cell adhesion, and vaso-occlusion, we have proposed a model that delineates how oxidative stress and inflammation contribute to the pathophysiology of vaso-occlusion in $\operatorname{SCD}(2,3)$. We hypothesize that $\mathrm{Hb}$, heme, and iron derived from hemolysis of sickle rbcs promote

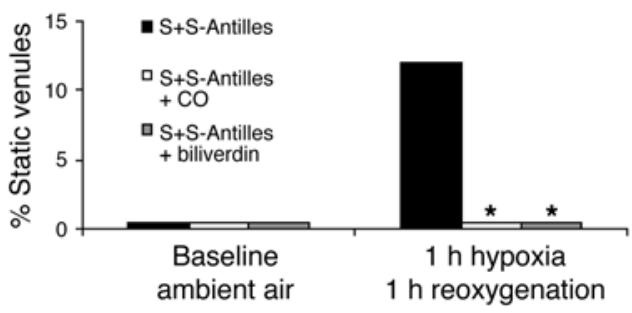

\section{Figure 4}

$\mathrm{CO}$ and biliverdin inhibit stasis in sickle mice. S+S-Antilles mice with an implanted DSFC were either untreated or treated with inhaled $\mathrm{CO}$ (250 ppm CO in air for 1 hour per day) for 3 days or biliverdin injections $(50 \mu \mathrm{mol} / \mathrm{kg}$ i.p. twice, at 16 hours and 2 hours, before hypoxia). Twenty-four hours after the third CO treatment or 2 hours after the second biliverdin injection, stasis was measured after 1 hour of hypoxia $\left(7 \% \mathrm{O}_{2} / 93 \% \mathrm{~N}_{2}\right)$ and 1 hour of reoxygenation in room air. $n=3-10$ mice and a minimum of 20 venules per mouse. ${ }^{*} P<0.05$, untreated versus $\mathrm{CO}$ or biliverdin. The proportions of venules exhibiting stasis at each time point were compared using a $z$ test. 


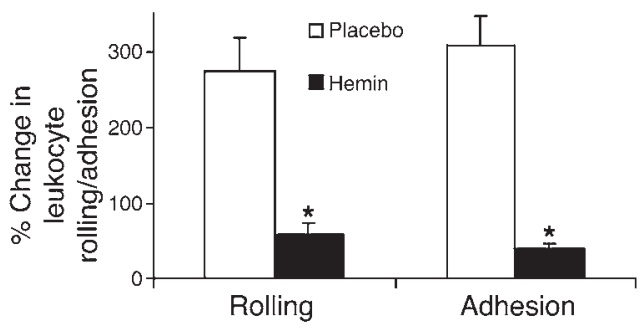

Figure 5

Further upregulation of $\mathrm{HO}-1$ by hemin inhibits hypoxia/reoxygenationinduced increases in leukocyte-endothelium interactions. S+S-Antilles mice with an implanted DSFC were treated with either placebo (saline) or hemin injections ( $40 \mu \mathrm{mol} / \mathrm{kg} / \mathrm{d}$, i.p.) for 3 days. Twenty-four hours after the third injection, leukocyte rolling and adhesion were measured in the subcutaneous venules at base line in ambient air and again in the same venules after exposure of the mice to 1 hour of hypoxia $\left(7 \% \mathrm{O}_{2} / 93 \% \mathrm{~N}_{2}\right)$ and 1 hour of reoxygenation in room air. Results are mean \pm SEM percentage change in leukocyte rolling and adhesion after hypoxia/reoxygenation. $n=2$ mice and a minimum of 20 venules per group. ${ }^{\star} P<0.05$, placebo versus hemin.

excessive ROS production, leading to EC activation and adhesion molecule expression on the vessel wall, which in turn promote the adhesion of sickle rbcs and leukocytes to endothelium, leading to vaso-occlusion. This paper demonstrates that the same pathophysiology induces adaptive cytoprotective proteins such as HO-1 in the endothelium that can ameliorate and prevent vaso-occlusion and the accompanying vascular inflammation commonly seen in SCD patients. We propose that it is the balance between these pro-oxidative and antioxidative forces that determines whether or not a vessel becomes occluded. In steady state these forces are likely balanced. However, a pro-oxidative insult such as hypoxia or an infection can easily tip the delicate balance in favor of hemolysis, oxidative stress, inflammation, and vaso-occlusion, causing the vessel wall to adapt by producing more cytoprotective proteins such as $\mathrm{HO}-1$, which put the vasculature back in a balanced steady state. Induction of HO- 1 arrives too late in the pathology of crises, and perhaps those patients that do not have significant clinical manifestations of the disease are those that have a greater homeostatic $\mathrm{HO}-1$ response.

HO-1 degrades heme, which not only removes a major catalytic source of ROS and oxidative stress but also at the same time produces $\mathrm{CO}$ and biliverdin, which have their own antiinflammatory effects. $\mathrm{CO}$ gas is produced by $\mathrm{HO}-1$-mediated opening of the heme ring. $\mathrm{CO}$ is a colorless, odorless gas that has traditionally been considered a dangerous poison. This toxicity is in part due to its high affinity for $\mathrm{Hb}$ (245 times greater than that of $\mathrm{O}_{2}$ ), which alters $\mathrm{O}_{2}$ transport and delivery. $\mathrm{CO}$ also can interact with other heme proteins as discussed below. At low concentrations $\mathrm{CO}$ can be therapeutic. $\mathrm{CO}$ mimics many of the protective effects of $\mathrm{HO}-1$, as well as some of the functions of $\mathrm{NO}(22,24)$. Like NO, CO activates the heme protein guanylate cyclase and inhibits platelet activation and aggregation $(22,24)$. CO participates in the regulation of vascular tone in hepatic sinusoidal cells, suggesting that NO and $\mathrm{CO}$ share control of these relaxation processes (49). Exogenous inhaled CO, at approximately $250 \mathrm{ppm}$, and in some studies as low as $10 \mathrm{ppm}$ (50), reduces inflammatory responses in several models of oxidant injury in ways similar to those of HO-1 overex-
A

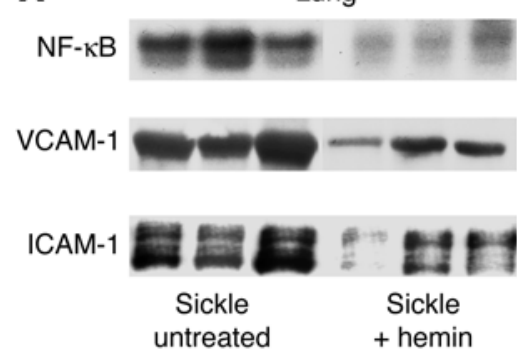

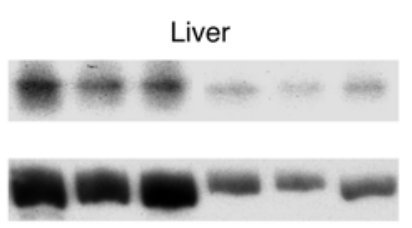

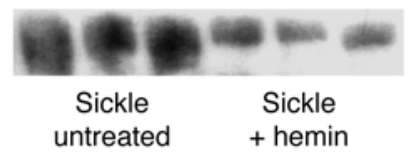

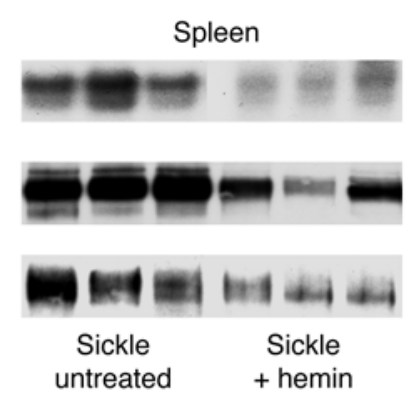

B

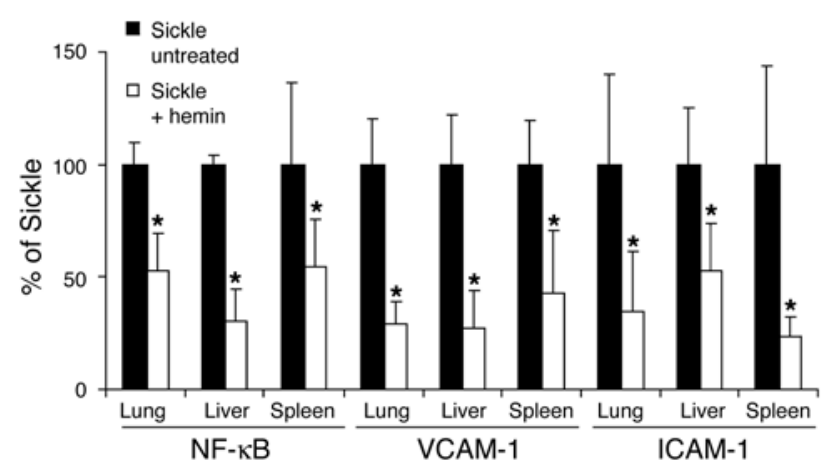

Figure 6

Further upregulation of $\mathrm{HO}-1$ by hemin inhibits NF-KB activation and VCAM-1 and ICAM-1 overexpression in the organs of sickle mice. $\mathrm{S}+\mathrm{S}$-Antilles mice were either untreated or injected with hemin $(40 \mu \mathrm{mol} / \mathrm{kg} / \mathrm{d}$, i.p.) for 3 days. Twenty-four hours after the third injection, the organs were harvested from mice in ambient air. NF- $\mathrm{KB}$ activation was measured by EMSA, and VCAM-1 and ICAM- 1 expression was measured by Western blotting in organ homogenates of the lungs, liver, and spleen of sickle mice. (A) The NF-KB, VCAM-1, and ICAM-1 bands are shown for each organ and each sickle mouse. (B) The bar graph shows the mean band intensity ( $n=3$ mice per group) \pm SD for each organ treatment group. ${ }^{\star} P<0.05$, untreated versus hemin. 


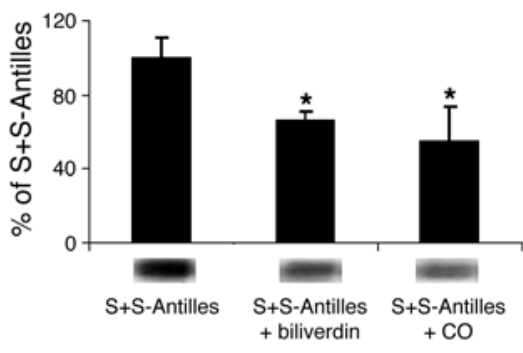

Figure 7

Biliverdin or $\mathrm{CO}$ treatment inhibits NF-kB activation in the lungs of sickle mice. S+S-Antilles mice were untreated, treated with biliverdin injections $(50 \mu \mathrm{mol} / \mathrm{kg}$ i.p. twice, at 16 hours and 2 hours), or treated with inhaled $\mathrm{CO}$ ( $250 \mathrm{ppm}$ in air for 1 hour per day for 3 days). Two hours after the second biliverdin injection or 24 hours after the third $\mathrm{CO}$ treatment, mice were exposed to 3 hours of hypoxia $\left(7 \% \mathrm{O}_{2} / 93 \% \mathrm{~N}_{2}\right)$ and 2 hours of reoxygenation in room air. After 2 hours of reoxygenation, the lungs were harvested, and NF-KB activation was measured in organ homogenates by EMSA. $n=3$ mice per group. Below each bar is a representative NF-KB band from the EMSA. ${ }^{\star} P<0.05$, untreated versus biliverdin or $\mathrm{CO}$.

pression (22). Also, CO liberated by CO-releasing molecules significantly suppresses the inflammatory response elicited by LPS in cultured macrophages (51). Like NO (52), CO interacts with signal transduction pathways, inhibits proinflammatory genes, and augments antiinflammatory cytokines $(22,24,53,54)$. Specifically, it selectively activates p38 MAPK signaling pathways in a guanylate cyclase-independent manner $(22,53)$. CO also inhibits proliferation of VSMCs and has antiapoptotic effects on cells $(22,24)$.

As noted above, CO seems to play a role similar to that of NO. NO has taken an important role in the pathogenesis and therapy of $\operatorname{SCD}(34,55,56)$. SCD patients have a reduction in basal and stimulated NO production and bioavailability. The deficiency of NO is in part due to elevated plasma $\mathrm{Hb}$ and excessive ROS production in both SCD patients and transgenic sickle mice (34). Therapeutic $\mathrm{CO}$ may be more effective, because the efficacy of $\mathrm{NO}$ is hampered by its ability to form reactive nitrogen species. Under oxidative conditions, NO reacts with ROS, resulting in the formation of highly reactive $\mathrm{ONOO}^{-}$(peroxynitrite) (57). Peroxynitrite does not prevent or ameliorate disease like $\mathrm{NO}$ does but, in contrast, exacerbates oxidative inflammatory stress $(58,59)$. Unlike NO, CO does not contain any unpaired free electrons and is, therefore, relatively inert.

Studies over 30 years ago by Beutler (60) suggested that CO binding to hemoglobin $\mathrm{S}$ shifts the oxygen dissociation curve to the left and can actually inhibit hemoglobin S deoxygenation, hemoglobin S polymerization, and rbc hemolysis. Less hemolysis means less plasma $\mathrm{Hb}$, less oxidative stress, less vascular inflammation, enhanced bioavailability of $\mathrm{NO}$, and ultimately less vaso-occlusion. $\mathrm{NO}$ and peroxynitrite can induce $\mathrm{HO}-1$ activity and thus form a feedback loop, where CO takes over NO functions under conditions of oxidative stress (21). In our studies, inhaled CO was able to inhibit vasoocclusion in the skin and NF-кB activation in the lungs, suggesting a potential therapeutic benefit at low doses in SCD patients.

Another product of heme metabolism by HO-1, as noted above, is biliverdin. In mammals, biliverdin is rapidly converted by biliverdin reductase to bilirubin. Both biliverdin and bilirubin are antioxidants with probable physiological relevance in plasma and the extravascular space (61). Exogenous bilirubin has been demonstrated to be cytoprotective in models of ischemia/reperfusion injury $(22,24)$. At micro- molar concentrations, both biliverdin and bilirubin efficiently scavenge peroxyradicals and thereby inhibit lipid peroxidation $(62,63)$. Biliverdin and bilirubin also may counteract intracellular nitrosative stress reactions $(64,65)$. In our studies, biliverdin injected i.p. was able to inhibit vascular stasis in the skin and NF-кB activation in the lungs similarly to inhaled CO, suggesting that biliverdin also may have therapeutic benefits in SCD. Biliverdin reductase might also be involved in transcriptional regulation of HO-1 (66).

Some of HO-1's protective effects in sickle mice were likely due to ferritin induction. In our initial studies, the induction of $\mathrm{HO}-1$ was accompanied by the induction of apoferritin (18). Apoferritin, made up of heavy and light chains, protects cells by its capacity to bind 4,500 iron molecules and through its heavy chain ferroxidase activity $(23,67,68)$. Ferritin can store nonreactive $\mathrm{Fe}^{3+}$ in the core of the ferritin complex. This handling of catalytic $\mathrm{Fe}^{2+}$ is essential for ferritin's ability to protect cells against oxidative stress $(13,69,70)$ by interrupting Fenton chemistry, exemplified in the Haber-Weiss reaction for hydroxyl radical generation. Animal models that overexpress the $\mathrm{H}$-ferritin chain withstand ischemia/reperfusion injury and oxidative stress without the concomitant increase in HO-1 (71). In vivo models that increased $\mathrm{HO}-1$ by hemin or $\mathrm{Hb}$ injections all increased ferritin levels $(36,72,73)$. Dissecting the intimate relationship between HO-1, Fe release from heme, and ferritin has depended on the use of HO- 1 inhibitors and iron chelators. Additional studies in sickle mice are needed to dissect the relative contributions of HO-1 and ferritin to inhibition of oxidative stress, inflammation, and
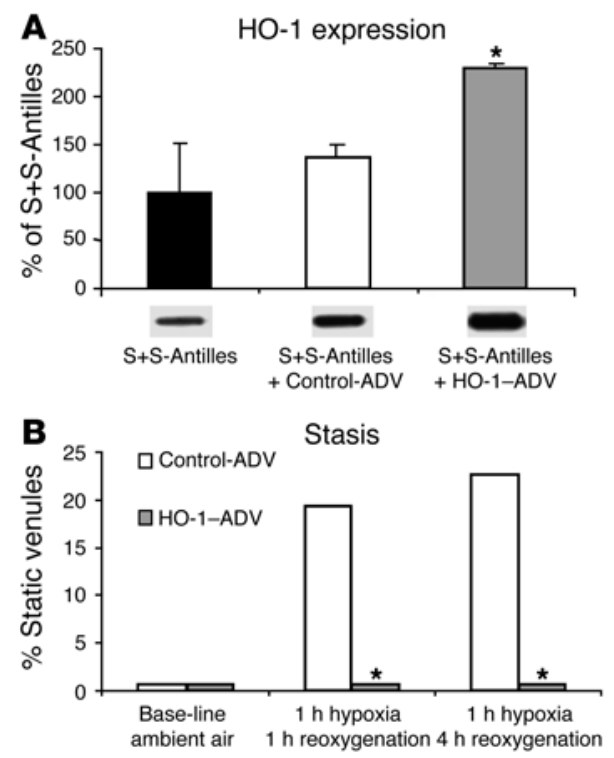

\section{Figure 8}

HO-1-ADV increases HO-1 expression and inhibits stasis. Local administration of HO-1-ADV increases $\mathrm{HO}-1$ expression $(\mathbf{A})$ and inhibits hypoxia/reoxygenation-induced stasis (B) in the skin. S+S-Antilles sickle mice with an implanted DSFC were treated with either a rat HO-1-ADV construct ( $n=3$ mice and 84 venules) or an empty Control-ADV construct ( $n=4$ mice and 64 venules). The adenovirus constructs $\left(2 \times 10^{7}\right.$ $\mathrm{MOI}$ ) in sterile saline were dripped onto the subcutaneous skin inside the DSFC. Forty-eight hours after adenovirus treatment, hypoxia/reoxygenation-induced stasis was measured (B). After measurement of stasis, the skin inside the DSFC window was harvested, and $\mathrm{HO}-1$ expression was measured in the skin homogenates by Western blotting (A). Below each bar is a representative $\mathrm{HO}-1$ band from the Western blot. ${ }^{*} P<0.05$, Control-ADV versus HO-1-ADV. 
vaso-occlusion in SCD. We conjecture that ferritin may be an important cytoprotectant in iron-burdened SCD animals and patients.

Other defenses against $\mathrm{Hb}$ and heme released into the vasculature include plasma haptoglobin and hemopexin. However, these defenses are likely overwhelmed in SCD, as evidenced by the low haptoglobin concentrations seen in our sickle mice and low plasma hemopexin levels in SCD patients (74-77). Moreover, the heme content and the overexpression of $\mathrm{HO}-1$ in organs of sickle mice suggest that this is indeed the case.

Markers of hemolysis are associated with a clinical subphenotype of pulmonary hypertension, leg ulceration, priapism, and risk of death in SCD patients $(78,79)$. Hemolysis may drive vasculopathy, but, by inducing HO-1 expression, hemolysis may ultimately limit vaso-occlusion. Perhaps HO-1 induction by hemolysis may explain the protection against atherosclerosis in SCD patients. Ironically, we used hemin, a "bad actor" in SCD, to therapeutically increase HO-1 and inhibit vascular inflammation and vaso-occlusion. Hematin therapy could be an approach in SCD patients. However, before HO-1 induction, hematin could potentially be pro-oxidative and also contribute to iron overload. Future therapeutic studies in our laboratory will focus on pharmacological therapies such as statins to increase HO-1 expression in SCD. Two recent papers demonstrated that some of the vasoprotective effects of statins, drugs used to decrease cholesterol and vascular inflammation in atherosclerosis, may be due to their ability to induce HO-1 $(80,81)$. Alternatively, direct administration of CO or biliverdin might be a therapeutic modality by which to treat or prevent sickle crises. In addition, functional polymorphisms in the HO-1 gene promoter region that control the ability to upregulate HO-1 $(82,83)$ could potentially explain some of the phenotypic differences in severity seen in SCD patients. These findings suggest that HO-1 and its products are promising new avenues of therapy in SCD.

\section{Methods}

Mice. All animal experiments were approved by the University of Minnesota's Institutional Animal Care and Use Committee. We used male and female S+S-Antilles (46) and BERK (47) transgenic sickle mice as our models for human SCD. S+S-Antilles mice are homozygous for deletion of the mouse $\beta$-major globin locus and express human $\alpha, \beta^{\mathrm{S}}$, and $\beta^{\text {s-Antilles }}$ globin transgenes. $\beta^{\text {S-Antilles }}$ globins contain, in addition to the $\beta^{\mathrm{S}}$ mutation at $\beta 6$, a second mutation at $\beta 23$ (Val $\rightarrow$ Ile). $\beta^{\text {S-Antilles }}$ has low oxygen affinity and decreased solubility under deoxygenated conditions, resulting in a more severe form of SCD. In S+S-Antilles mice, approximately $42 \%$ of the $\beta$ globins expressed are $\beta^{\mathrm{S}}$ and $36 \%$ are $\beta^{\mathrm{S} \text {-Antilles. }}$

BERK mice have full knockout of murine $\alpha$ and $\beta$ globins and replacement with a human $\alpha$ and $\beta^{s}$ globin transgene (47). BERK mice have more severe organ pathology than S+S-Antilles mice, exhibit multiorgan pathology, including areas of fibrosis and/or infarction in liver, kidney, and spleen, and have loss of urine-concentrating ability.

Normal male and female mice (C57BL/6) were used as genetic controls for the sickle mice. The mice used in these studies were 8-12 weeks of age. The mice weighed $20-30 \mathrm{~g}$ and were housed in specific pathogen-free housing to prevent common murine infections that could cause an inflammatory response. All the mice were maintained on a standard chow diet.

Treatments of mice. In experiments to either upregulate HO-1 expression or inhibit HO-1 activity, mice were injected i.p. with hemin (Sigma-Aldrich) or tin protoporphyrin (SnPP; Frontier Scientific Inc.), respectively, at a dose of $40 \mu \mathrm{mol} / \mathrm{kg} / \mathrm{d}$ for 3 days. HO-1, NF- $\mathrm{KB}, \mathrm{VCAM}-1$, and ICAM-1 were measured in organ homogenates, and hypoxia/reoxygenation-induced stasis and leukocyte rolling and adhesion were measured in the subcutaneous skin.
In experiments to evaluate the effects of $\mathrm{CO}$ and biliverdin, sickle mice were placed in a special chamber and exposed to an atmosphere of $\mathrm{CO}$ at a dose of 250 ppm CO in air (Air Products and Chemicals Inc.) for 1 hour per day for 3 days or were injected with biliverdin (Frontier Scientific Inc.) at a dose of $50 \mu \mathrm{mol} / \mathrm{kg}$ i.p. twice, at 16 hours and 2 hours, before harvesting of lungs or exposure to hypoxia $\left(7 \% \mathrm{O}_{2} / 93 \% \mathrm{~N}_{2}\right)$. Twenty-four hours after the third inhaled $\mathrm{CO}$ treatment or 2 hours after the second biliverdin injection, NF-KB was measured in lung homogenates, and hypoxia/reoxygenation-induced stasis was measured in the subcutaneous skin.

In experiments to further evaluate the effect of HO-1 upregulation on stasis, S+S-Antilles sickle mice with an implanted DSFC were treated with either a rat HO-1 adenovirus construct (HO-1-ADV) or an empty control adenovirus (Control-ADV). The recombinant adenovirus containing rat HO-1 cDNA was generated as previously described (38). The adenovirus constructs $\left(2 \times 10^{7} \mathrm{MOI}\right)$ in sterile saline were dripped onto the subcutaneous skin inside the DSFC. Forty-eight hours after adenovirus treatment, hypoxia/reoxygenation-induced stasis was measured.

After the treatments described above, sickle mice with an implanted DSFC were exposed to hypoxia/reoxygenation to measure vascular stasis or leukocyte rolling and adhesion. After base-line measurements in room air, sickle mice were placed in a special chamber and exposed to 1 hour of hypoxia $\left(7 \% \mathrm{O}_{2} / 93 \% \mathrm{~N}_{2}\right)$ followed by reoxygenation in room air for 1 hour. The measurements were repeated in the same venules after exposure to hypoxia/reoxygenation. The sickle mice could tolerate the brief (1-hour) exposure to hypoxia without dying.

Markers of hemolysis. Hematocrit levels and reticulocytes were measured in EDTA blood collected from the tail veins of mice as previously described (43). Plasma Hb was measured by Drabkin's reagent. Plasma haptoglobin was measured by Western blotting, and total plasma bilirubin was measured colorimetrically by the diazo bilirubin method (84).

Mouse tissue collection. The mice in ambient air were sacrificed and tissues harvested as previously described (2). Mice were asphyxiated in a $\mathrm{CO}_{2}$ chamber for approximately 60 seconds. Samples of lungs, livers, and spleens were taken for homogenate preparation. Organ samples for homogenate preparation were immediately frozen in liquid nitrogen and stored at $-80^{\circ} \mathrm{C}$. Organ samples also were collected for histopathology.

Organ heme content. The heme content of lungs and livers was measured in organ homogenates by the pyridine-hemochrome method (35).

Western blots of lung, liver, and spleen HO-1, VCAM-1, and ICAM-1. Lung, liver, and spleen tissue samples were collected and frozen as described above. Thawed tissues were homogenized and homogenate DNA concentrations were measured as previously described (2). Tissue homogenates containing an equal amount of homogenate DNA per well were subjected to SDSPAGE (7.5\%). After SDS-PAGE, the samples were transferred electrophoretically to PVDF membranes, and immunoblotting of the organ homogenates was performed with rabbit anti-rat HO-1 antiserum (Stressgen Biotechnologies Inc.), or goat anti-mouse VCAM-1 or ICAM-1 IgG directed against the C-terminus of the target protein (Santa Cruz Biotechnology Inc.). Sites of primary antibody binding were visualized with HRP-conjugated donkey anti-rabbit or anti-goat IgG (Jackson ImmunoResearch Laboratories Inc.). The final detection of immunoreactive bands was performed using a chemiluminescent detection substrate (Pierce).

EMSA for NF- $\mathrm{\kappa} B$ activation. NF- $\mathrm{KB}$ activation was measured in organ extracts by EMSA as previously described (2). To confirm the identity of NF- $\mathrm{B}$ bands, some reactions were run with an excess of unlabeled consensus or mutant double-stranded DNA (dsDNA) for competition experiments or with antibodies to the p50 or p65 subunit of NF-KB for supershift experiments. The mutant dsDNA for NF- $\mathrm{KB}$ differed by $1 \mathrm{bp}$ from the consensus binding sequence. A 10 -fold excess of mutant dsDNA added to the binding reaction was unable to inhibit binding of the radiolabeled consensus dsDNA 
sequence to NF- $\mathrm{kB}$, while a 10 -fold excess of unlabeled consensus dsDNA completely abolished binding of the radiolabeled consensus dsDNA. Mouse NF-кB EMSA bands contained the p50 and p 65 subunits (data not shown).

Quantitation of Western blots and EMSAs. To quantitate expression of HO-1, VCAM-1, ICAM-1, and NF-кB, exposed films of chemiluminescent Western blots and radioactive gel shifts were scanned on a GS-700 Imaging Densitometer (Bio-Rad Laboratories Inc.). Bands on each image were quantified with Molecular Analyst software (version 2.1; Bio-Rad Laboratories Inc.) using local background subtraction. The intensity of HO-1, VCAM-1, and ICAM-1 bands on film was linear between 25 and 1,000 ng of tissue homogenate DNA with correlation coefficients $\left(r^{2}\right)$ of $1.00,1.00$, and 0.98 , respectively. The intensity of NF- $\kappa B$ bands on film was linear between 12 and $500 \mathrm{ng}$ of tissue homogenate DNA with a correlation coefficient $\left(r^{2}\right)$ of 0.98 . This permitted accurate quantitation of the relative intensities of HO-1, VCAM-1, ICAM-1, and NF-KB bands on film and their corresponding levels of tissue expression.

Measurement of vascular stasis. Hypoxia/reoxygenation-induced stasis of venular blood flow in the subcutaneous skin was measured in mice with an implanted DSFC using intravital microscopy as previously described $(2,43)$. All measurements of blood flow parameters in the DSFC were made 4-7 days after DSFC implantation. At base line, with the mice in ambient air, flowing venules were selected at random, and their relative locations were noted on a map of the microscopic field. After base-line selection of flowing venules in ambient air, the mice were subjected to 1 hour of hypoxia $\left(7 \% \mathrm{O}_{2} / 93 \% \mathrm{~N}_{2}\right)$, followed by reoxygenation in room air. After 1 and 4 hours of reoxygenation, the same venules were reexamined for blood flow. Venules with no observable blood flow were counted as static. The percentage of static vessels was calculated by division of the number of static venules at any given time point by the total number of flowing venules selected at base line. A minimum of 20 subcutaneous venules were examined in each mouse. We equate vascular stasis with vaso-occlusion for experimental purposes. Certainly, prolonged vaso-occlusion seen clinically is associated with activation of coagulation and thrombosis leading to organ infarction.

Leukocyte rolling and adhesion. Leukocyte-endothelium interactions were measured in venules of the subcutaneous skin after staining of leukocytes in vivo with the intravital fluorescent dye rhodamine $6 \mathrm{G}$ as previously described $(2,43,85)$. S+S-Antilles mice with an implanted DSFC were treated with either placebo (saline) or hemin injections $(40 \mu \mathrm{mol} / \mathrm{kg} / \mathrm{d}$, i.p.) for 3 days. Twenty-four hours after the third injection, leukocyte rolling and adhesion were measured in the subcutaneous venules at base line in room air and again after exposure of the mice to 1 hour of hypoxia $\left(7 \% \mathrm{O}_{2} / 93 \% \mathrm{~N}_{2}\right)$ and 1 hour of reoxygenation in room air. The rolling flux was determined as the total number of leukocytes rolling through a given section of vessel per minute. To assess leukocyte adhesion, $100-\mu \mathrm{m}$ venular segments were examined, and a leukocyte was considered adherent if it remained stationary for at least 30 seconds (4). Results are expressed as the percentage change in leukocyte rolling and adhesion after hypoxia/reoxygenation. A minimum of 20 vessels were examined in each mouse.

$\mathrm{CO}-\mathrm{Hb}$ and met-Hb. Oximeters (682 [Instrumentation Laboratory] and ABL 700 [Radiometer America Inc.], respectively) were used to measure CO-Hb and met-Hb levels in blood samples collected by cardiac puncture (86).

Statistics. All statistical analyses were performed with SigmaStat 2.0 for Windows (SPSS). Comparisons of data groups were made using a 2 -tailed Student's $t$ test or a Mann-Whitney rank sum test. The proportions of venules exhibiting stasis at each time point were compared using a $z$ test. $P$ values less than or equal to 0.05 were considered statistically significant.

\section{Acknowledgments}

This work was supported by National Heart, Lung, and Blood Institute grants HL67367 and HL55552. We would like to thank Stephana Choong for breeding and characterizing the transgenic sickle mice used for these studies.

Received for publication September 15, 2005, and accepted in revised form December 13, 2005.

Address correspondence to: John D. Belcher, University of Minnesota, Division of Hematology, Oncology and Transplantation, Department of Medicine, MMC 480, 420 Delaware Street SE, Minneapolis, Minnesota 55455, USA. Phone: (612) 624-2611; Fax: (612) 625-6919; E-mail: belcher@umn.edu.
1. Nagel, R.L., and Fabry, M.E. 2001. The panoply of animal models for sickle cell anaemia. Br. J. Haematol. 112:19-25.

2. Belcher, J.D., et al. 2005. Critical role of endothelial cell activation in hypoxia-induced vasoocclusion in transgenic sickle mice. Am. J. Physiol. Heart Circ. Physiol. 288:H2715-H2725.

3. Mahaseth, H., et al. 2005. Polynitroxyl albumin inhibits inflammation and vasoocclusion in transgenic sickle mice. J. Lab. Clin. Med. 145:204-211.

4. Kaul, D.K., and Hebbel, R.P. 2000. Hypoxia/reoxygenation causes inflammatory response in transgenic sickle mice but not in normal mice. J. Clin. Invest. 106:411-420.

5. Kaul, D.K., et al. 2004. Anti-inflammatory therapy ameliorates leukocyte adhesion and microvascular flow abnormalities in transgenic sickle mice. Am.J. Physiol. Heart Circ. Physiol. 287:H293-H301.

6. Embury, S.H., et al. 2004. The contribution of endothelial cell P-selectin to the microvascular flow of mouse sickle erythrocytes in vivo. Blood. 104:3378-3385.

7. Turhan, A., Weiss, L.A., Mohandas, N., Coller, B.S., and Frenette, P.S. 2002. Primary role for adherent leukocytes in sickle cell vascular occlusion: a new paradigm. Proc. Natl. Acad. Sci. U. S. A. 99:3047-3051.

8. Setty, B.N., and Stuart, M.J. 1996. Vascular cell adhesion molecule- 1 is involved in mediating hypoxia-induced sickle red blood cell adherence to endothelium: potential role in sickle cell disease. Blood. 88:2311-2320.
9. Lavrovsky, Y., Chatterjee, B., Clark, R.A., and Roy, A.K. 2000. Role of redox-regulated transcription factors in inflammation, aging and age-related diseases. Exp. Gerontol. 35:521-532.

10. Park, H.S., et al. 2004. Cutting edge: direct interaction of TLR4 with NAD(P)H oxidase 4 isozyme is essential for lipopolysaccharide-induced production of reactive oxygen species and activation of NF-kappa B. J. Immunol. 173:3589-3593.

11. Victor, V.M., Rocha, M., and De la Fuente, M. 2003. $\mathrm{N}$-acetylcysteine protects mice from lethal endotoxemia by regulating the redox state of immune cells. Free Radic. Res. 37:919-929.

12. Chen, X.L., Zhang, Q., Zhao, R., and Medford, R.M 2004. Superoxide, $\mathrm{H} 2 \mathrm{O} 2$, and iron are required for TNF-alpha-induced MCP-1 gene expression in endothelial cells: role of Rac1 and NADPH oxidase. Am. J. Physiol. Heart Circ. Physiol. 286:H1001-H1007.

13. Balla, J., et al. 2003. Haem, haem oxygenase and ferritin in vascular endothelial cell injury. Nephrol. Dial. Transplant. 18:v8-v12.

14. Balla, G., Vercellotti, G., Eaton, J.W., and Jacob, H.S 1990. Heme uptake by endothelium synergizes polymorphonuclear granulocyte-mediated damage. Trans. Assoc. Am. Physicians. 103:174-179.

15. Balla, G., Vercellotti, G.M., Eaton, J.W., and Jacob, H.S. 1990. Iron loading of endothelial cells augments oxidant damage. J. Lab. Clin. Med. 116:546-554.

16. Bunn, H.F., and Jandl, J.H. 1968. Exchange of heme among hemoglobins and between hemoglobin and albumin. J. Biol. Chem. 243:465-475.
17. Hebbel, R.P., Morgan, W.T., Eaton, J.W., and Hedlund, B.E. 1988. Accelerated autoxidation and heme loss due to instability of sickle hemoglobin. Proc. Natl. Acad. Sci. U. S. A. 85:237-241.

18. Balla, G., et al. 1992. Ferritin: a cytoprotective antioxidant strategem of endothelium. J. Biol. Chem. 267:18148-18153.

19. Rublevskaya, I., and Maines, M.D. 1994. Interaction of Fe-protoporphyrin IX and heme analogues with purified recombinant heme oxygenase-2, the constitutive isozyme of the brain and testes. J. Biol. Chem. 269:26390-26395.

20. McCoubrey, W.K., Jr., Huang, T.J., and Maines, M.D. 1997. Isolation and characterization of a cDNA from the rat brain that encodes hemoprotein heme oxygenase-3. Eur. J. Biochem. 247:725-732.

21. Maines, M.D. 1997. The heme oxygenase system: a regulator of second messenger gases. Annu. Rev. Pharmacol. Toxicol. 37:517-554.

22. Otterbein, L.E., Soares, M.P., Yamashita, K., and Bach, F.H. 2003. Heme oxygenase-1: unleashing the protective properties of heme. Trends Immunol. 24:449-455.

23. Harrison, P.M., and Arosio, P. 1996. The ferritins: molecular properties, iron storage function and cellular regulation. Biochim. Biophys. Acta. 1275:161-203.

24. Wagener, F.A., et al. 2003. Different faces of the heme-heme oxygenase system in inflammation. Pharmacol. Rev. 55:551-571.

25. Yachie, A., et al. 1999. Oxidative stress causes enhanced endothelial cell injury in human heme 
oxygenase-1 deficiency. J. Clin. Invest. 103:129-135.

26. Wagener, F.A., et al. 2001. Heme is a potent inducer of inflammation in mice and is counteracted by heme oxygenase. Blood. 98:1802-1811.

27. Kawashima, A., Oda, Y., Yachie, A., Koizumi, S., and Nakanishi, I. 2002. Heme oxygenase-1 deficiency: the first autopsy case. Hum. Pathol. 33:125-130.

28. Soares, M.P., et al. 2004. Heme oxygenase-1 modulates the expression of adhesion molecules associated with endothelial cell activation. J. Immunol. 172:3553-3563.

29. Wagener, F.A., et al. 1999. Differential effects of heme oxygenase isoforms on heme mediation of endothelial intracellular adhesion molecule 1 expression. J. Pharmacol. Exp. Ther. 291:416-423.

30. Hayashi, S., et al. 1999. Induction of heme oxygenase-1 suppresses venular leukocyte adhesion elicited by oxidative stress: role of bilirubin generated by the enzyme. Circ. Res. 85:663-671.

31. Vachharajani, T.J., Work,J., Issekutz,A.C., and Granger, D.N. 2000. Heme oxygenase modulates selectin expression in different regional vascular beds. Am.J. Physiol. Heart Circ. Physiol. 278:H1613-H1617.

32. Rucker, M., et al. 2001. Reduction of inflammatory response in composite flap transfer by local stress conditioning-induced heat-shock protein 32. Surgery. 129:292-301.

33. Wang, X., et al. 2004. Biological activity of nitric oxide in the plasmatic compartment. Proc. Natl. Acad. Sci. U. S. A. 101:11477-11482.

34. Reiter, C.D., et al. 2002. Cell-free hemoglobin limits nitric oxide bioavailability in sickle-cell disease. Nat. Med. 8:1383-1389.

35. Berry, E.A., and Trumpower, B.L. 1987. Simultaneous determination of hemes $a, b$, and $c$ from pyridine hemochrome spectra. Anal. Biochem. 161:1-15.

36. Balla, J., et al. 1995. Endothelial cell heme oxygenase and ferritin induction in rat lung by hemoglobin in vivo. Am. J. Physiol. 268:L321-L327.

37. Belcher, J.D., et al. 2003. Transgenic sickle mice have vascular inflammation. Blood. 101:3953-3959.

38. Otterbein, L.E., et al. 1999. Exogenous administration of heme oxygenase- 1 by gene transfer provides protection against hyperoxia-induced lung injury. J. Clin. Invest. 103:1047-1054.

39. Nath, K.A., et al. 2001. Oxidative stress and induction of heme oxygenase- 1 in the kidney in sickle cell disease. Am. J. Pathol. 158:893-903.

40. Jison, M.L., et al. 2004. Blood mononuclear cell gene expression profiles characterize the oxidant, hemolytic, and inflammatory stress of sickle cell disease. Blood. 104:270-280.

41. Nagel, R.L. 1994. Lessons from transgenic mouse lines expressing sickle hemoglobin. Proc. Soc. Exp. Biol. Med. 205:274-281.

42. Osarogiagbon, U.R., et al. 2000. Reperfusion injury pathophysiology in sickle transgenic mice. Blood. 96:314-320.

43. Kalambur, V.S., et al. 2004. Microvascular blood flow and stasis in transgenic sickle mice: utility of a dorsal skin fold chamber for intravital microscopy. Am. J. Hematol. 77:117-125.

44. Embury, S.H., Mohandas, N., Paszty, C., Cooper, P., and Cheung, A.T. 1999. In vivo blood flow abnormalities in the transgenic knockout sickle cell mouse. J. Clin. Invest. 103:915-920.

45. Kaul, D.K., Fabry, M.E., Costantini, F., Rubin, E.M., and Nagel, R.L. 1995. In vivo demonstration of red cell-endothelial interaction, sickling and altered microvascular response to oxygen in the sickle transgenic mouse. J. Clin. Invest. 96:2845-2853.

46. Fabry, M.E., et al. 1995. A second generation transgenic mouse model expressing both hemoglobin S (HbS) and HbS-Antilles results in increased phenotypic severity. Blood. 86:2419-2428.

47. Paszty, C., et al. 1997. Transgenic knockout mice with exclusively human sickle hemoglobin and sickle cell disease. Science. 278:876-878.

48. Manci, E.A., et al. 2005. Pathology of "Berkeley" sickle cell mice: similarities and differences with human sickle cell disease. Blood. doi:10.1182/blood2005-07-2839.

49. Hata, K., et al. 2003. Induction of heme oxygenase1 and dilation of hepatic sinusoids by an administration of pyrrolidine dithiocarbamate in rat livers. J. Surg. Res. 115:310-317.

50. Sarady, J.K., et al. 2004. Carbon monoxide protection against endotoxic shock involves reciprocal effects on iNOS in the lung and liver. FASEB J. 18:854-856.

51. Sawle, P., et al. 2005. Carbon monoxide-releasing molecules (CO-RMs) attenuate the inflammatory response elicited by lipopolysaccharide in RAW264.7 murine macrophages. Br. J. Pharmacol. 145:800-810.

52. Marshall, H.E., Hess, D.T., and Stamler, J.S. 2004. S-nitrosylation: physiological regulation of NF-kappaB. Proc. Natl. Acad. Sci. U. S. A. 101:8841-8842.

53. Ryter, S.W., Otterbein, L.E., Morse, D., and Choi, A.M. 2002. Heme oxygenase/carbon monoxide signaling pathways: regulation and functional significance. Mol. Cell. Biochem. 234-235:249-263.

54. Ohta, K., and Yachie, A. 2004. Development of vascular biology over the past 10 years: heme oxygenase- 1 in cardiovascular homeostasis. J. Endovasc. Ther. 11(Suppl. 2):II140-II150.

55. Gladwin, M.T., and Schechter, A.N. 2001. Nitric oxide therapy in sickle cell disease. Semin. Hematol. 38:333-342.

56. Reiter, C.D., and Gladwin, M.T. 2003. An emerging role for nitric oxide in sickle cell disease vascular homeostasis and therapy. Curr. Opin. Hematol. 10:99-107.

57. Wolin, M.S., Davidson, C.A., Kaminski, P.M., Fayngersh, R.P., and Mohazzab, H.K. 1998. Oxidant-nitric oxide signalling mechanisms in vascular tissue. Biochemistry Mosc. 63:810-816.

58. Beckman, J.S., and Crow, J.P. 1993. Pathological implications of nitric oxide, superoxide and peroxynitrite formation. Biochem. Soc. Trans. 21:330-334.

59. Beckman, J.S., and Koppenol, W.H. 1996. Nitric oxide, superoxide, and peroxynitrite: the good, the bad, and ugly. Am. J. Physiol. 271:C1424-C1437.

60. Beutler, E. 1975. The effect of carbon monoxide on red cell life span in sickle cell disease. Blood. 46:253-259.

61. Stocker, R., McDonagh, A.F., Glazer, A.N., and Ames, B.N. 1990. Antioxidant activities of bile pigments: biliverdin and bilirubin. Methods Enzymol. 186:301-309.

62. Stocker, R., Yamamoto, Y., McDonagh, A.F., Glazer, A.N., and Ames, B.N. 1987. Bilirubin is an antioxidant of possible physiological importance. Science. 235:1043-1046.

63. Dailly, E., Urien, S., Barre, J., Reinert, P., and Tillement, J.P. 1998. Role of bilirubin in the regulation of the total peroxyl radical trapping antioxidant activity of plasma in sickle cell disease. Biochem. Biophys. Res. Commun. 248:303-306.

64. Kaur, H., et al. 2003. Interaction of bilirubin and biliverdin with reactive nitrogen species. FEBS Lett. 543:113-119.

65. Mancuso, C., Bonsignore, A., Di Stasio, E., Mordente, A., and Motterlini, R. 2003. Bilirubin and S-nitrosothiols interaction: evidence for a possible role of bilirubin as a scavenger of nitric oxide. Biochem. Pharmacol. 66:2355-2363.

66. Miralem, T., Hu, Z., Torno, M.D., Lelli, K.M., and Maines, M.D. 2005. Small interference RNA-mediated gene silencing of human biliverdin reductase, but not that of heme oxygenase-1, attenuates arsenite-mediated induction of the oxygenase and increases apoptosis in 293A kidney cells. J. Biol. Chem. 280:17084-17092.
67. Theil, E.C. 2003. Ferritin: at the crossroads of iron and oxygen metabolism. J. Nutr. 133:1549S-1553S. 68. Arosio, P., and Levi, S. 2002. Ferritin, iron homeostasis, and oxidative damage. Free Radic. Biol. Med. 33:457-463.

69. Cozzi, A., et al. 2000. Overexpression of wild type and mutated human ferritin $\mathrm{H}$-chain in HeLa cells: in vivo role of ferritin ferroxidase activity. J. Biol. Chem. 275:25122-25129.

70. Epsztejn, S., et al. 1999. H-ferritin subunit overexpression in erythroid cells reduces the oxidative stress response and induces multidrug resistance properties. Blood. 94:3593-3603.

71. Berberat, P.O., et al. 2003. Heavy chain ferritin acts as an antiapoptotic gene that protects livers from ischemia reperfusion injury. FASEB J. 17:1724-1726.

72. Erario, M.A., Gonzales, S., Noriega, G.O., and Tomaro, M.L. 2002. Bilirubin and ferritin as protectors against hemin-induced oxidative stress in rat liver. Cell. Mol. Biol. (Noisy-le-grand). 48:877-884.

73. Gonzales, S., Erario, M.A., and Tomaro, M.L. 2002. Heme oxygenase- 1 induction and dependent increase in ferritin. A protective antioxidant stratagem in hemin-treated rat brain. Dev. Neurosci. 24:161-168.

74. Foidart, M., Liem, H.H., Adornato, B.T., Engel, W.K., and Muller-Eberhard, U. 1983. Hemopexin metabolism in patients with altered serum levels. J. Lab. Clin. Med. 102:838-846.

75. Wochner, R.D., Spilberg, I., Iio, A., Liem, H.H., and Muller-Eberhard, U. 1974. Hemopexin metabolism in sickle-cell disease, porphyrias and control subjects: effects of heme injection. N. Engl. J. Med. 290:822-826.

76. Fertakis, A., Panitsas, G., and Angelopoulos, B. 1973. Serum haemopexin concentration in patients with various haemoglobinopathies. Effect of splenectomy. Acta Haematol. 50:149-153.

77. Muller-Eberhard, U., Javid, J., Liem, H.H., Hanstein, A., and Hanna, M. 1968. Plasma concentrations of hemopexin, haptoglobin and heme in patients with various hemolytic diseases. Blood. 32:811-815.

78. Kato, G.J., et al. 2005. Lactate dehydrogenase as a biomarker of hemolysis-associated nitric oxide resistance, priapism, leg ulceration, pulmonary hypertension and death in patients with sickle cell disease. Blood. doi:10.1182/blood-2005-06-2373.

79. Nolan, V.G., Wyszynski, D.F., Farrer, L.A., and Steinberg, M.H. 2005. Hemolysis-associated priapism in sickle cell disease. Blood. 106:3264-3267.

80. Lee, T.S., Chang, C.C., Zhu, Y., and Shyy, J.Y. 2004. Simvastatin induces heme oxygenase-1: a novel mechanism of vessel protection. Circulation. 110:1296-1302.

81. Grosser, N., et al. 2004. The antioxidant defense protein heme oxygenase 1 is a novel target for statins in endothelial cells. Free Radic. Biol. Med. 37:2064-2071.

82. Exner, M., Minar, E., Wagner, O., and Schillinger, M. 2004. The role of heme oxygenase- 1 promoter polymorphisms in human disease. Free Radic. Biol. Med. 37:1097-1104.

83. Exner, M., et al. 2001. Heme oxygenase-1 gene promoter microsatellite polymorphism is associated with restenosis after percutaneous transluminal angioplasty. J. Endovasc. Ther. 8:433-440.

84. Martinek, R.G. 1966. Improved micro-method for determination of serum bilirubin. Clin. Chim. Acta. 13:161-170.

85. Baatz, H., Steinbauer, M., Harris, A.G., and Krombach, F. 1995. Kinetics of white blood cell staining by intravascular administration of rhodamine 6G. Int. J. Microcirc. Clin. Exp. 15:85-91.

86. Mahoney, J.J., Vreman, H.J., Stevenson, D.K., and Van Kessel, A.L. 1993. Measurement of carboxyhemoglobin and total hemoglobin by five specialized spectrophotometers (CO-oximeters) in comparison with reference methods. Clin. Chem. 39:1693-1700. 